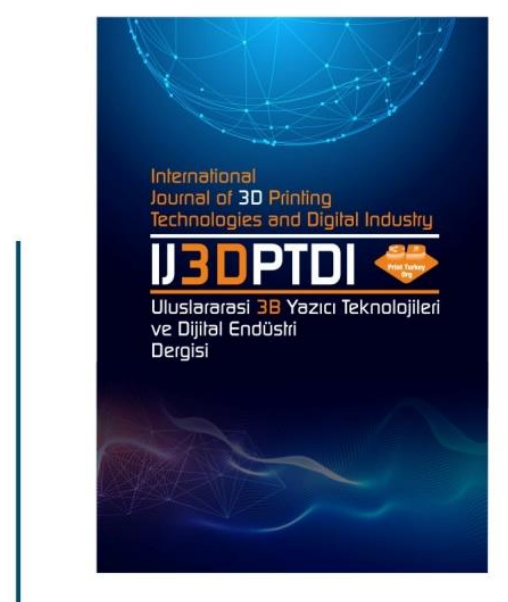

ULUSLARARASI 3B YAZICI TEKNOLOJILERI

VE DIJITAL ENDÜSTRI DERGISI

INTERNATIONAL JOURNAL OF 30 PRINTING TECHNQLOGIES AND DIGITAL INDUSTRY

I55N:2602-3350 [Online]

URL: https://dergipark.org.tr/ij3dptdi

\title{
MECHANICAL EVALUATION OF 3D PRINTED POLY(CAPROLACTONE) SCAFFOLDS: EFFECT OF MOLECULAR WEIGHT
}

Yazarlar (Authors): Murat Taner Vurat (D), Mahmut Parmaksiz * (D)

Bu makaleye şu şekilde atıfta bulunabilirsiniz (To cite to this article): Vurat M.T., Parmaksiz M." Mechanical Evaluation Of 3d Printed Poly(Caprolactone) Scaffolds: Effect Of Molecular Weight" Int. J. of 3D Printing Tech. Dig. Ind., 5(2): 251-258, (2021). 


\title{
MECHANICAL EVALUATION OF 3D PRINTED POLYCAPROLACTONE SCAFFOLDS: EFFECT OF MOLECULAR WEIGHT
}

\author{
Murat Taner Vurat a ${ }^{(i D}$, Mahmut Parmaksiz ${ }^{a, b *}$ (iD) \\ ${ }^{a}$ Ankara University, Faculty of Science, Tissue Engineering, Biomaterials and Nanobiotechnology Laboratory, \\ Ankara, TURKEY \\ ${ }^{\mathrm{b}}$ Ankara University, Stem Cell Institute, Ankara, TURKEY \\ *Corresponding Author: parmaksiz@ankara.edu.tr
}

(Received: 08.07.2021; Revised: 11.08.2021; Accepted: 17.08.2021)

\begin{abstract}
Three-dimensional (3D) scaffold fabrication with appropriate architectural and mechanical properties is one of the critical components of tissue engineering. There are many traditional/conventional scaffold fabrication techniques such as electrospinning, gas foaming, freeze-drying etc. More recently, there has been increasing interest in the use of 3D printing technologies in scaffold fabrication for tissue engineering application. With the use of 3D printing technology, scaffolds with desired porosity and target damage/tissue architecture can be developed. Various 3D printing based scaffold production studies by using different types of synthetic or natural polymers are available in the literature. In the selection of polymers to be used for printing, parameters such as target scaffold mechanical properties, porosity and solubility should be considered. For example, it is well known that the molecular weights of the polymers can significantly affect the final scaffold mechanical properties. In this study, the effects of molecular weight and nozzle moving speed on the mechanical and physical properties of 3D printed scaffolds were evaluated. For this purpose, biocompatible PCL polymer with different molecular weights was used and ten-layered scaffolds were fabricated at different nozzle speeds. Then, mechanical, morphological and physical properties of the printed scaffolds were analyzed.
\end{abstract}

Keywords: Printing, Three dimensional, Scaffold, Poly(e-caprolactone), Mechanical behaviour,

\section{INTRODUCTION}

One of the basic components of tissue engineering approach is the development of 3D structures called scaffolds that can mimic the biological and mechanical properties of the target tissue. Scaffolds used in tissue engineering applications are expected to have suitable mechanical properties, as well as high biocompatibility, easy processing, interconnected porosity and optimal degradation rate etc. [1]. Until now, various natural polymers (collagen, elastin, gelatin, hyaluronic acid etc.), decellularized xenogenic/allogeneic extracellular matrices (ECM), synthetic biocompatible polymers (PCL, PLGA, PVA etc.) or bioceramics (TCP, HAp etc.) have been used for scaffold fabrication [2-4]. Natural polymers have relatively limitations such as insufficient mechanical properties or processability. Contrary, synthetic polymers have important advantages such as adjustable mechanical properties, low degradation rate and suitability for mass production [5]. So far, synthetic polymer-based scaffolds have been developed for different tissue engineering applications with traditional methods (electrospinning, salt-casting, freeze-drying etc.) [2]. However, it is relatively difficult to fabricate the scaffolds with controllable porosity and mechanical properties, especially with an architectural structure specific to target tissue damage area by using the traditional methods.

Besides that, 3D printing technologies, which are already widely used in the industry, have become increasingly common in tissue engineering scaffold production. It has been possible to fabricate the scaffolds that are designed via computed tomography images specific to the target damage area with 3D printing systems [6]. Thanks to this technology, 3D scaffolds for different tissues with controllable and interconnected pores, complex structure and geometry can be fabricated with high sensitivity and the 
limitations encountered in traditional production methods can be overcome. Although there are several 3D printing systems such as extrusion, laser or inkjet based to fabricate scaffolds, ink/material alternatives that can be used in tissue engineering scaffold production are limited [7-9]. The materials to be used in 3D printing should be chosen considering the targeted scaffolding architecture and composition. In addition, the printability, solubility and mechanical properties of the materials to be used for this purpose are absolute critical for the scaffold properties. Natural polymers such as gelatin, collagen, alginate are often used as ink in 3D bioprinting applications where cells or biological molecules are included [7,10]. However, the insufficient mechanical strength of hydrogel-based 3D scaffold and the requirement for post-printing cross-linking are still important limitations. It is seen that synthetic polymers are commonly used in scaffold production in 3D printing applications, as in traditional methods. On the other hand, 3D printing studies with synthetic polymers pointed out that the scaffolds produced from melt or using different solvent systems exhibit different sensitivity and mechanical behaviors [11-13]. So, the properties of the final product could be changed significantly with polymer properties. This situation complicates the selection of the optimal polymers that can be used in $3 \mathrm{D}$ printing based scaffold production. In this context, it is reported that PCL, which is a semi-crystalline biocompatible polymer that is easily soluble in organic solvents and has a relatively low melting point of $60^{\circ} \mathrm{C}$, is frequently used in $3 \mathrm{D}$ printing applications with its remarkable features $[2,14,15]$. On the other hand, since the molecular weight of PCL can range from 500 to $120,000 \mathrm{Da}$, the specific selection for the printing method (extrusion vs. inkjet) is critical considering the target scaffold design, desired mechanical properties and porosity.

In this context, the aim of the study was to fabricate 3D printed ten-layered scaffolds by using PCL having different molecular weights $(\mathrm{Mw})$ and to evaluate the effects of $\mathrm{Mw}$ and nozzle moving speed on physical properties of 3D printed scaffold such as mechanical behavior, fiber size, pore size etc.

\section{MATERIALS AND METHODS}

\subsection{Materials}

PCL granules with four different molecular weights $(\mathrm{Mw}=12,500,25,000,42,500$ and 80,000 Da) were purchased from Sigma Aldrich (St. Louis, MO, USA). Unless otherwise mentioned all equipment and apparatus used in the 3D printing process were purchased from Cellink Co. Ltd, (Gothenburg, Sweden) Also in this study, an Inkredible+ extrusion based 3D printing system was used to fabricate PCL based scaffolds.

\subsection{Design and fabrication of scaffolds}

Ten-layered PCL scaffolds (33 x 33 × $6 \mathrm{~mm}$ ) were created by computer-aided design. Each layer in the scaffold consists of 13 parallel struts connected to each other and each strut has a diameter of approximately 750 micrometers. The struts forming two consecutive layers are positioned at an angle of 90 degrees to each other. After completion of the design, slicing process was performed using Slic $3 \mathrm{r}$ software (version 1.2.9).
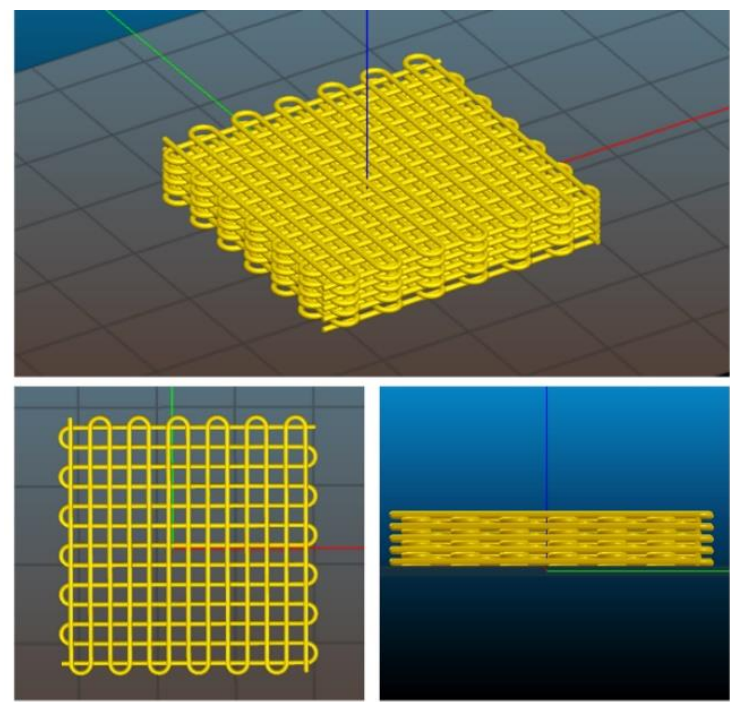

Figure 1. Design of ten-layered scaffold structure 
To perform the printing of ten-layered scaffolds, PCL pellets were loaded into an aluminum cartridge with $21 \mathrm{G}$ (Inner diameter; $0.609 \mathrm{~mm}$ ) conical nozzle and device was set to $100^{\circ} \mathrm{C}$ for melting the PCL pellets. After the cartridge reached $100^{\circ} \mathrm{C}$, the printing process of scaffolds was started. The printing process was carried out on a glass petri dish under constant $60 \mathrm{kPa}$ pneumatic pressure and various nozzle moving speeds $(1 \mathrm{~mm} / \mathrm{s}$ and $2.5 \mathrm{~mm} / \mathrm{s})$ until the entire printing process was completed. All parameters related to 3D printing of PCL scaffolds are also presented in Table 1.

Table 1. Properties of 3D printing process and 3D printed scaffolds.

\begin{tabular}{ccc}
\hline Properties & Unit & Value \\
\hline Scaffold size & $\mathrm{mm}$ & $33 \times 33 \times 6$ \\
Layer height & $\mathrm{mm}$ & 0.6 \\
Molecular weight of PCL & $\mathrm{kDa}$ & $12.5,25,42.5$ and 80 \\
Nozzle moving speed & $\mathrm{mm} \mathrm{s}^{-1}$ & 1 and 2.5 \\
Extruder temperature & ${ }^{\circ} \mathrm{C}$ & 100 \\
Pneumatic pressure & $\mathrm{kPa}$ & 60 \\
Nozzle diameter & $\mathrm{mm}$ & 0.609 \\
\hline
\end{tabular}

All these 3D printing processes were also applied to PCL pellets with four different molecular weights $(\mathrm{Mw}=12,500,25,000,42,500$ and $80,000 \mathrm{Da})$ and besides $1 \mathrm{~mm} / \mathrm{s}$ and $2.5 \mathrm{~mm} / \mathrm{s}$ nozzle moving speed was also performed for each printing. It was aimed to fabricate four different types of scaffold structures using all the mentioned parameters. The scaffold types were named according to the molecular weight of the used PCL pellets and the applied nozzle moving speed as given in Table 2. After completion of the $3 \mathrm{D}$ printing processes the printed scaffolds were allowed to cool at room temperature.

Table 2. Experimental groups

\begin{tabular}{cccc}
\hline Groups & Mw (kDa) & Nozzle moving speed (mm/s) & Pressure (kPa) \\
\hline 1 & 25 & 1 & 60 \\
2 & 25 & 2.5 & 60 \\
3 & 42.5 & 1 & 60 \\
4 & 42.5 & 2.5 & 60 \\
\hline
\end{tabular}

\subsection{Morphological characterizations}

Following the 3D printing process, the surface morphologies of the ten-layered PCL scaffolds, the diameter of struts and pore/strut size in the scaffolds were evaluated by using a Carl Zeiss EVO-40 model scanning electron microscope (SEM) (Carl Zeiss AG, Oberkochen, Germany). 3D printed PCL scaffolds were sputter coated with a thin layer of gold (60s) to form conductive surface and were examined at different magnifications. In addition, the distribution and resolution of struts and pores in the scaffold structures were also examined by inverted microscopy.

\subsection{Mechanical analysis}

The mechanical properties of 3D printed ten-layered PCL scaffolds were investigated using an AGS-X model universal test machine with $500 \mathrm{~N}$ load capacity (Shimadzu Corporation, Kyoto, Japan) and uniaxial compression test was performed. Samples with a size of $10 \times 10 \mathrm{~mm}$ and a height of $6 \mathrm{~mm}$ were used and the compression tests were carried out at a strain of $50 \%$. The crosshead speed was set to 1 $\mathrm{mm} / \mathrm{min}$. A minimum of four samples for each group was tested. The averages of data were given as stress-strain curve and maximum force/stress values. 


\subsection{Statistics}

All results were presented as mean \pm standard deviation (SD). Statistical analyses were performed using one-way analysis of variance and Tukey's post-hoc test. A $p$-value $<0.05(*)$ was considered statistically significant. All analyses were carried out using GraphPad Prism version 8.0 (GraphPad Software, San Diego, CA).

\section{RESULTS AND DISCUSSION}

In this study, PCL scaffolds with grid structure were fabricated using a 3D printing system with two different nozzle moving speed and different molecular weights of PCL. The 3D printed PCL scaffolds were examined macroscopically to evaluate the macro-structural integrity. The macroscopic images of 3D printed PCL scaffolds are shown in Figure 2. According to the images, it is clear that all of the PCL scaffolds were similar to the designed 3D grid model and had a side length of $\sim 3 \mathrm{~cm}$. In Groups 1, 3 and 4 , it was seen that all 10 layers in the 3D scaffold structure were successfully formed. On the contrary, deformations and non-continuous struts were observed in the other layers except the first layer in Group 2 .

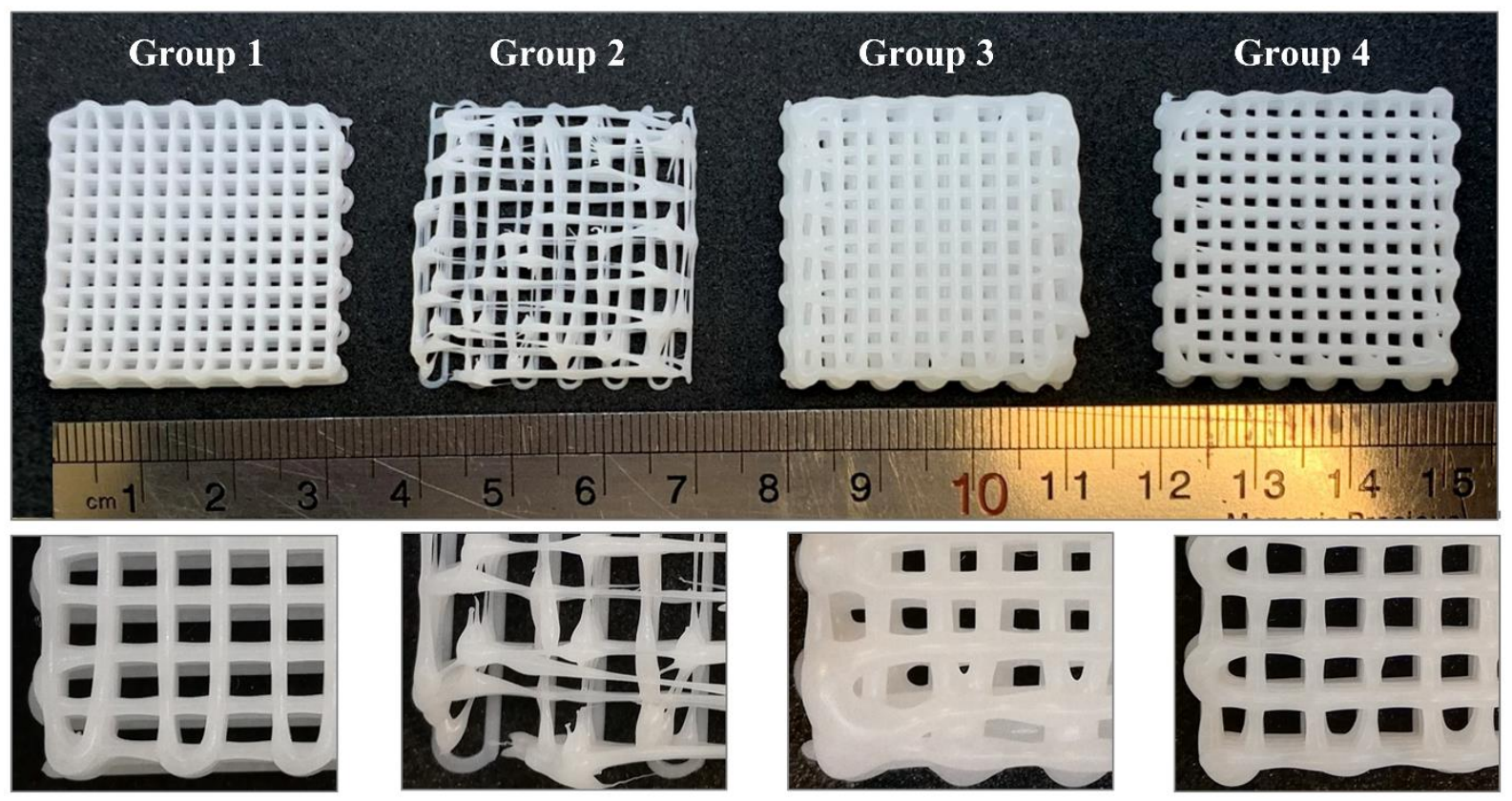

Figure 2. Macroscopic images of 3D printed PCL scaffolds

In addition to macroscopic observations, SEM analysis was performed to examine the diameters, microintegrity and distance of the struts in the structure. SEM micrographs are presented in Figure 3. Also, some of the physical properties of scaffolds are presented in Table 3. The retrieved SEM images support the macroscopic findings. In the top-view and cross-section SEM images of samples from Group 1, 3 and 4 , it was observed that the struts had high printing quality. As seen in the Figure 3B, thickness of the struts in the 3D printed scaffold were not homogenous at every part of the scaffold, and therefore the pore sizes of structure also differed.

The viscosity of the molten PCL polymer depends on its molecular weight. For this reason, molten PCL with high molecular weight should be printed with higher pneumatic pressure [16]. In this study, PCL, which had $80 \mathrm{kDa}$ molecular weight could not be printed under applied constant $60 \mathrm{kPA}$ extrusion pressure and $100^{\circ} \mathrm{C}$ temperature conditions. Likewise, scaffolds could not be printed successfully using the low molecular weight PCL (Mw:12.5 kDa), which had very low viscosity [12,14]. Also, according to SEM images, it was determined that the strut diameters in Group 1 and Group 4 samples were quite similar, and the structural integrity of both samples was highly preserved. 

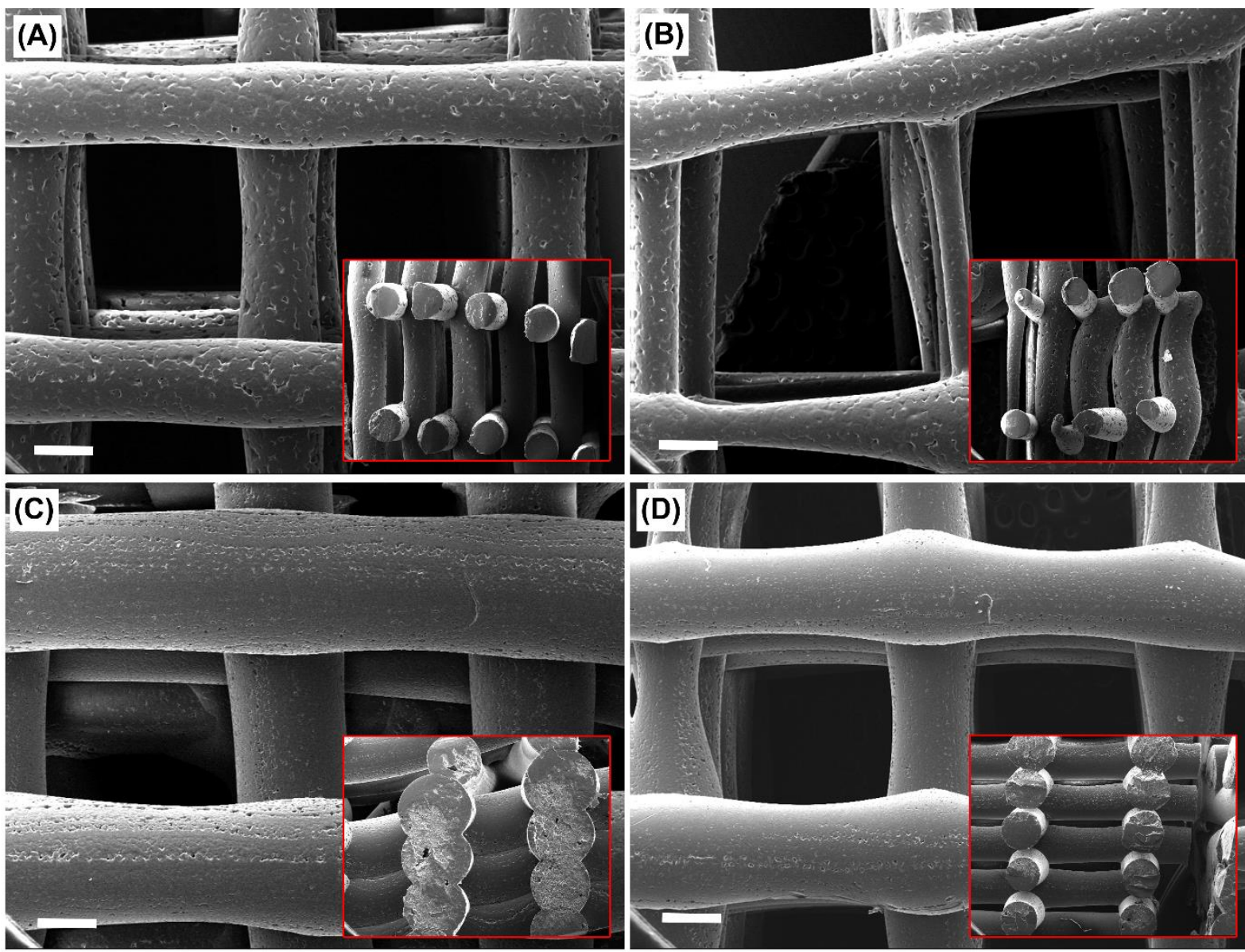

Figure 3. Top view and cross-section of SEM micrographs of 3D printed PCL scaffolds A:Group 1, B:Group 2, C: Group 3 and D: Group 4 (Scale bars $=500 \mu \mathrm{m})$.

When the physical properties of the 3D printed PCL structures were examined, the strut diameters of Group 1 and Group 4 samples are quite close to each other. Also, it was found that there was no significant difference between these two groups in terms of pore sizes, weights and heights of the scaffolds. As expected, results showed that, when the nozzle moving speed was increased by using polymers with the same molecular weight polymers, the diameter of the struts decreased and thus the pore size increased [12,17] For example, while the average strut diameter in Group 1 (25 kDa Mw and $1 \mathrm{~mm} / \mathrm{s}$ ) was $702.93 \pm 33.38 \mu \mathrm{m}$, the fiber diameter decreased to an average of $540 \pm 81.27 \mu \mathrm{m}$ with the increase of the speed (Group 2). Accordingly, the average pore size value increased from $1623.25 \pm$ 98.90 to $2389.75 \pm 326.99 \mu \mathrm{m}$.

Table 3. Physical properties and results from SEM analysis of 3D printed PCL scaffolds.

\begin{tabular}{ccccc}
\hline & $\begin{array}{c}\text { Strut Diameter } \\
(\boldsymbol{\mu m})\end{array}$ & $\begin{array}{c}\text { Pore Size } \\
(\boldsymbol{\mu m})\end{array}$ & $\begin{array}{c}\text { Scaffold Weight } \\
(\mathbf{m g})\end{array}$ & $\begin{array}{c}\text { Scaffold Height } \\
(\mathbf{m m})\end{array}$ \\
\hline Group 1 & $702.93 \pm 33.38$ & $1623.25 \pm 98.90$ & $1.83 \pm 0.035$ & $4.97 \pm 0.405$ \\
Group 2 & $540.10 \pm 81.27$ & $2389.75 \pm 326.99$ & $0.88 \pm 0.045$ & $4.59 \pm 0.55$ \\
Group 3 & $1283.3 \pm 184.04$ & $1445.75 \pm 251.53$ & $3.90 \pm 0.195$ & $5.85 \pm 0.29$ \\
Group 4 & $833.78 \pm 178.16$ & $1756.00 \pm 116.37$ & $2.06 \pm 0.075$ & $4.59 \pm 0.29$ \\
\hline
\end{tabular}

The compressive properties of the 3D printed PCL scaffolds were also evaluated. Mechanical test results including stress-strain curves, maximum force and maximum stress of scaffolds are presented in Figure 4. Results showed that, the four groups of scaffolds have different mechanical properties. Eventually, 
3D printed scaffolds in Groups 3 had higher compressive strength value then other groups. With the increase of molecular weight, 3D printed scaffolds gained higher compressive strength. In other studies, similar changes in the mechanical compressive properties are observed by the increase of $\mathrm{Mw}$ and nozzle moving speed [17]. In particular, the difference in mechanical properties can be modulated by using different molecular weight polymers for optimal design of the 3D printed scaffolds [18].
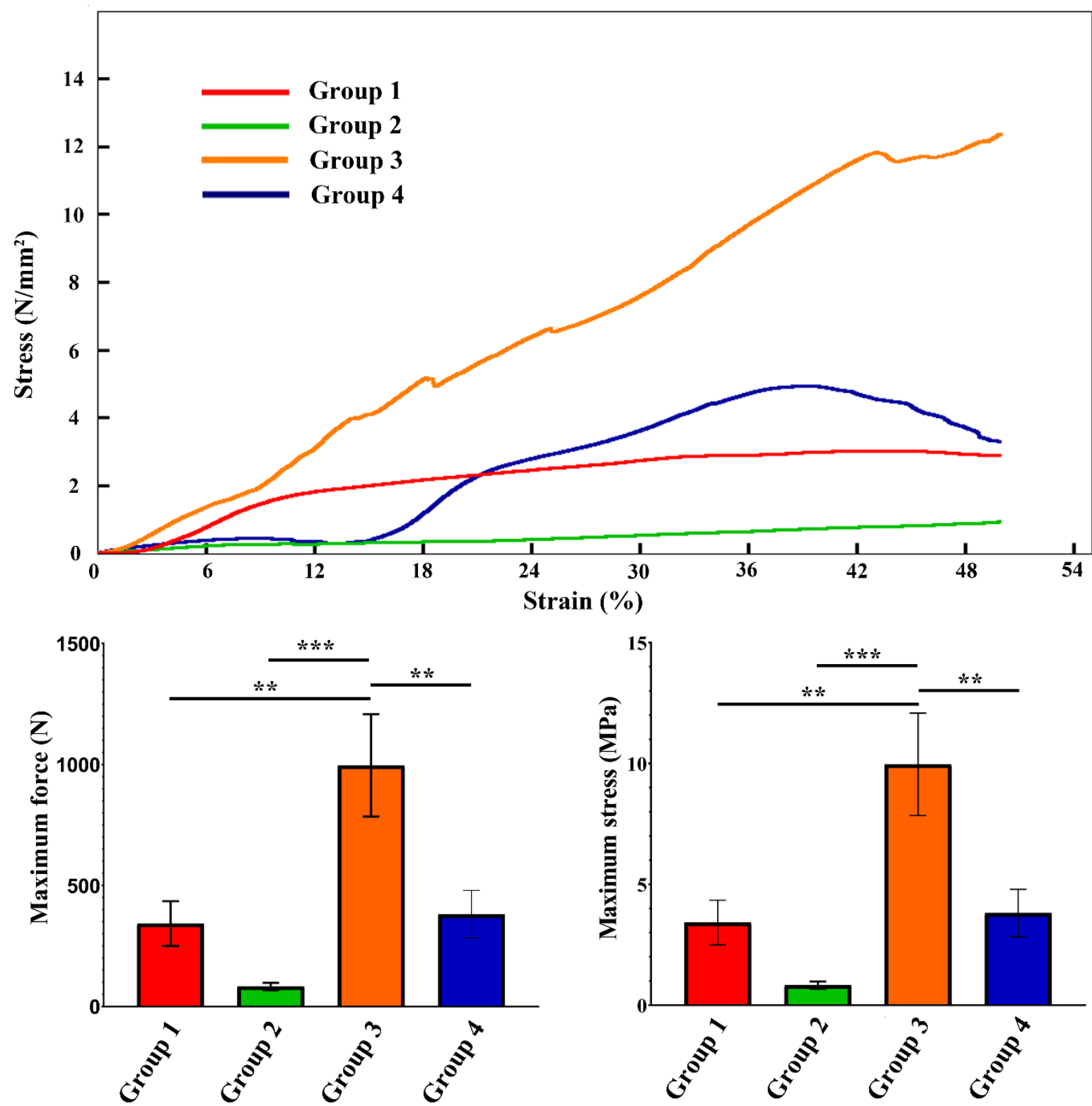

Figure 4. Mechanical compression test results of 3D printed PCL scaffolds.

A: Stress-Strain curves, B: Maximum Force, C: Maximum Stress $(* * \mathrm{p}<0.01, * * * \mathrm{p}<0.001)$

\section{CONCLUSION}

Herein, the properties of the scaffolds fabricated using two different nozzle moving speeds of printing and PCL polymer with different molecular weights were compared. The effects of nozzle moving speed of printing process and molecular weight of the PCL polymer on scaffold properties were evaluated at $60 \mathrm{kPa}$ pressure and $100^{\circ} \mathrm{C}$ temperature.

In summary, findings revealed that the scaffolds fabricated using $25 \mathrm{kDa}$ and $42.5 \mathrm{kDa} \mathrm{Mw}$ PCL were quite similar to the designed 3D model. There were some differences in the properties of the 3D printed scaffolds depending on the nozzle moving speed and PCL viscosity. However, significant differences were observed in the mechanical properties of the 3D printed scaffolds. Although the resolutions of the 
3D printed scaffolds fabricated with $1 \mathrm{~mm} / \mathrm{s}$ nozzle moving speed and $42.5 \mathrm{kDa}$ PCL were partially low, it was found that they had the highest mechanical compressive strength.

\section{ACKNOWLEDGMENTS}

We sincerely thank Prof. Y.M. Elçin and Prof. A.E. Elçin for their endless support.

\section{REFERENCES}

1. Elçin, Y.M. "Stem Cells and Tissue Engineering", Biomaterials. Advances in Experimental Medicine and Biology, Springer, Boston, MA. Vol. 553, 2004.

2. Vurat, M.T., Elcin, A.E. and Elcin, Y.M. "Osteogenic composite nanocoating based on nanohydroxyapatite, strontium ranelate and polycaprolactone for titanium implants", Transactions of Nonferrous Metals Society of China, Vol. 28, Issue 9, Pages 1763-1773, 2018.

3. Parmaksiz, M., Lalegül-Ülker, Ö., Vurat, M.T., Elçin, A.E. and Elçin, Y.M. "Magneto-sensitive decellularized bone matrix with or without low frequency-pulsed electromagnetic field exposure for the healing of a critical-size bone defect", Material Science and Engineering: C, May;124:112065. doi: 10.1016/j.msec.2021.112065. Epub 2021 Mar 26. PMID: 33947558. 2021.

4. Kang, Y., Mochizuki, N., Khademhosseini, A., Fukuda, J. and Yang, Y. "Engineering a vascularized collagen- $\beta$-tricalcium phosphate graft using an electrochemical approach", Acta Biomaterialia, Vol. 11, Pages 449-458, 2015.

5. Parmaksiz, M., Elcin, A.E. and Elcin, Y.M. "Decellularized bovine small intestinal submucosaPCL/hydroxyapatite-based multilayer composite scaffold for hard tissue repair", Materials Science and Engineering: C, Vol. 94, Pages 788-797, 2019.

6. Vurat, M.T., Şeker, Ş., Lalegül-Ülker, Ö., Parmaksiz, M., Elçin, A. E. and Elçin, Y.M. "Development of a multicellular 3D-bioprinted microtissue model of human periodontal ligament-alveolar bone biointerface: Towards a pre-clinical model of periodontal diseases and personalized periodontal tissue engineering", Genes \& Diseases. 2020.

7. Vurat, M.T., Ergun, C., Elcin, A.E. and Elçin, Y.M. "3D Bioprinting of Tissue Models with Customized Bioinks", In Bioinspired Biomaterials, Springer, Singapore, Pages 67-84, 2020.

8. Soufivand, A.A., Abolfathi, N., Hashemi, A. and Lee, S.J. "The effect of 3D printing on the morphological and mechanical properties of polycaprolactone filament and scaffold", Polymers for Advanced Technologies, Vol. 31, Issue 5, Pages 1038-1046, 2020.

9. Murphy, S. and Atala, A. "3D bioprinting of tissues and organs", Nature Biotechnology, Vol. 32, Pages 773$785,2014$.

10. She, Y., Fan, Z., Wang, L., Li, Y., Sun, W., Tang, H., Zhang, L., Wu, L., Zheng, H. and Chen, C. "3D Printed Biomimetic PCL Scaffold as framework interspersed with collagen for long segment tracheal replacement", Frontiers in cell and developmental biology, Vol. 9, Page 33, 2021.

11. Zimmerling, A., Yazdanpanah, Z., Cooper, D.M., Johnston, J.D. and Chen, X. "3D printing PCL/nHA bone scaffolds: exploring the influence of material synthesis techniques", Biomaterials Research, Vol. 25, Issue 1, Pages 1-12, 2021.

12. Olubamiji, A.D., Izadifar, Z., Si, J.L., Cooper, D.M., Eames, B.F. and Chen, D.X. "Modulating mechanical behaviour of 3D-printed cartilage-mimetic PCL scaffolds: influence of molecular weight and pore geometry", Biofabrication, Vol. 8 Issue 2, Pages 025020. 2016.

13. Doyle, S.E., Henry, L., McGennisken, E., Onofrillo, C., Bella, C.D., Duchi, S., O'connell, C.D. and Pirogova, E. "Characterization of Polycaprolactone Nanohydroxyapatite Composites with Tunable Degradability Suitable for Indirect Printing", Polymers, Vol. 13, Issue 2, Pages 295. 2021. 
14. Ferreira, J., Gloria, A., Cometa, S., Coelho, J.F. and Domingos, M. "Effect of in vitro enzymatic degradation on 3D printed poly ( $\varepsilon$-caprolactone) scaffolds: Morphological, chemical and mechanical properties", Journal of applied biomaterials \& functional materials, Vol. 15, Issue 3, Pages 185-195, 2017.

15. Cho, Y.S., Gwak, S.J. and Cho, Y.S. "Fabrication of Polycaprolactone/Nano Hydroxyapatite (PCL/nHA) 3D Scaffold with Enhanced In Vitro Cell Response via Design for Additive Manufacturing (DfAM) ", Polymers, Vol. 13, Issue 9, Pages 1394, 2021.

16. Sodupe Ortega, E., Sanz-Garcia, A., Pernia-Espinoza, A. and Escobedo-Lucea, C. "Efficient Fabrication of Polycaprolactone Scaffolds for Printing Hybrid Tissue-Engineered Constructs", Materials (Basel, Switzerland), Vol. 12, Issue 4, Pages 613, 2019.

17. Geng, P., Zhao, J., Wu, W., Ye, W., Wang, Y., Wang, S. and Zhang, S. "Effects of extrusion speed and printing speed on the 3D printing stability of extruded PEEK filament", Journal of Manufacturing Processes, Vol. 37, Pages 266-273, 2019.

18. Hendrikson, W.J., Rouwkema, J., Van Blitterswijk, C.A. and Moroni, L. "Influence of PCL molecular weight on mesenchymal stromal cell differentiation”, RSC Advances, Vol. 5, Issue 67, Pages 54510-54516, 2015. 